\title{
A SOCIOLOGICAL APPROACH TO THE HISTORY OF MEDICINE*
}

\author{
by
}

\section{THOMAS MCKEOWN}

WHAT HISTORY can teach is a much-discussed question and historians themselves are divided about the answer; what medical history can teach is a question which is not often asked and yet there can be little doubt about the answer. The direction of medical effort, both in service and research, is seriously prejudiced because of lack of the perspective which historical investigation could and should provide.

The provision of this perspective, I suggest, should be the main aim of the social historian and I have taken my title from Sigerist's essay on 'The Social History of Medicine' written in 1940. He wrote: 'I would like to draw your attention to a field of studies in the history of medicine that has been greatly neglected in the past. If you open a textbook, any textbook of medical history, and try to find what health conditions were in rural France in the eighteenth century, or what disease meant to the family of an artisan at the same period, you will as a rule not find any information. We know much about the great medical discoveries but very little on whether they were applied or to whom they were applied.' Sigerist ended his essay with these words: 'I think that the sociological approach to the history of medicine not only gives us a better understanding of the past but can also help us in planning the future.' On this interpretation, if social history is history with the politics left out, the social history of medicine is medical history with the public interest put in.

It is not difficult to suggest why this interest has hitherto been lacking. Those who have taken up the study of medical history have done so mainly for love of history; being fascinated by the lives and work of men such as Hippocrates, Galen and Osler, they seem scarcely to have noticed that these giants were unable to treat anything effectively. In consequence, histories of medicine, like histories of art, have two main themes, the great men and the great movements: Leonardo and the High Renaissance; Pasteur and the rise of bacteriology. A case could be made for the view that the best statistician is the one who dislikes figures and the safest surgeon the one who does not enjoy operating; perhaps the most successful social historian would be one who does not particularly care for history, but turns to it because he considers it indispensable to an understanding of contemporary problems. From this viewpoint the social history of medicine is much more than a blend of social history and medical history, more than medical developments seen in the social context of their period; it is essentially an operational approach which takes its terms of reference from difficulties confronting medicine in the present day. It is the lack of such insight, derived from contemporary experience, which makes a good deal of medical history so sterile for the uninitiated.

* The Inaugural Lecture of the Society for the Social History of Medicine, presented at the Society's first meeting, held at the Wellcome Institute of the History of Medicine, 8 May 1970. 


\section{A Sociological Approach to the History of Medicine}

I shall devote the remainder of this paper to discussion of some problems which seem to me to illustrate the scope of the work which awaits the attention of the social historian.

\section{INFLUENCES ON MAN'S HEALTH}

Since the time of Kepler and Harvey medical thought has been dominated by the belief that improvements in health must rely on an engineering approach, chiefly chemical or mechanical, based on an understanding of the structure and function of the body and the disease processes which affect it. This concept has been largely responsible for the significance attached to the work of the acute hospital and for the relative neglect of psychiatric, geriatric and some other forms of care; it has had a powerful influence on the direction of medical research. If the concept remains unchallenged, it is probable that these trends will be exaggerated in future and that medicine will become still more sharply divided into favoured and depressed areas, based on a division between technology and care.

It is therefore imperative that there should be a critical evaluation of the influences on which human health depends. Such an investigation must be largely historical, an examination of the conditions under which man developed and of the major influences which affected health at different stages of his evolution. I believe the conclusions will lead to a picture very different from the one which has been predominant since the seventeenth century.

\section{WHAT DOCTORS HAVE BEEN DOING}

Many non-medical writers have not hesitated to make their own evaluation of the medical measures of their day and some have arrived at low estimates. The views of Montaigne and Shaw, for example, are particularly explicit; those of Tolstoy in War and Peace include a characteristically profound appraisal of the medical task as well as a judgement on the ineffectiveness of treatment.

In spite of the literary distinction of the critics, such opinions have been largely ignored by medical people, or regarded as so perverse that they do not merit serious consideration. Historians in particular have shown little interest in assessment of the character of doctors' work and the extent of their achievement at different periods in history; in general they have been interested in what was done rather than in whether it was worth doing.

As a background to present and future developments in medicine it seems essential to put the work and achievement of the past into much clearer perspective. The following analysis suggests the lines such an inquiry might take and a few tentative conclusions derived from it.

The tasks on which doctors have been traditionally engaged may be classified as followed.

1. Diagnosis or identification of disease. Although several diseases were recognized with more or less certainty at an earlier date (for example smallpox, plague, dysentery, tetanus, rabies, gonorrhoea and syphilis), reliable identification of disease began in the nineteenth century.

2. Pathology or understanding of disease. In spite of earlier advances in related 


\section{Thomas McKeown}

sciences such as anatomy and physiology, an accurate understanding of disease processes was delayed until the nineteenth century. It owed much to recognition of the bacterial origin of infections.

3. Prevention of disease. Although some reforms were anticipated earlier, effective preventive measures began with the control of the environment in the second half of the nineteenth century. Vaccination against smallpox was the only means of preventing disease in the individual before 1900.

4. Cure of disease. Effective treatment began in the twentieth century. Some useful drugs were introduced much earlier (for example, mercury, iron, quinine and digitalis) but the circumstances and manner of their use, and the limited grasp of their mode of action suggest that they must have been relatively ineffective. Before the discovery of anaesthesia, operations were mainly for cataracts, amputations, incisions for abscesses, lithotomy and trephining of the skull. Even after the introduction of anaesthetics, results were poor until aseptic techniques became widely used.

5. Prognosis, or anticipation of the probable results of disease. As a science, prognosis, which must rest on numerical evidence, can hardly yet be said to exist. Clinical impressions have of course been recorded, but they have only recently begun to be submitted to critical scrutiny.

6. Palliation or alleviation of the effects of disease. If relief of both physical and mental suffering are included under palliation, this is certainly the oldest and, at least until the nineteenth century, the most important medical service.

From the point of view of the public, (1) and (2) are only means to the ends listed under (3) to (6); and of these ends only the last (palliation) can be said to have been achieved before the nineteenth century. With the exception of vaccination against smallpox it seems unlikely that any specific measure of prevention or treatment was effective until the present century.

It will be evident that the analysis provided here is quite inadequate, a mere outline of a subject which requires full and careful investigation. But it is perhaps enough to show the lines such an inquiry might take and the type of conclusions to which it could lead. Apart from its intrinsic interest, an accurate assessment of medical work and achievement could have a powerful effect on contemporary thinking. It is instructive to learn that at all stages of history doctors have over-estimated the results of their intervention; to be reminded that diagnosis and understanding of disease are of no value to society until they lead to prevention or treatment; to know that effective therapy was not available before the twentieth century and we must look elsewhere for an explanation of the large improvement in health which occurred earlier.

\section{REASONS FOR IMPROVEMENT IN HUMAN HEALTH}

Interpretation of improvement in health since the eighteenth century is among the most important subjects in history; yet so far it has had little attention from medical writers. Some have been interested in the decline of individual infectious diseases such as plague, smallpox, typhus, scarlet fever, and typhoid; but there have been few attempts to assess the contribution of medical and other influences to mortality as a whole, or the relation of mortality to the growth of population. So 


\section{A Sociological Approach to the History of Medicine}

the inquiry has been left mainly to economic historians and demographers who have been interested in the improvement in health only in so far as it throws light on other issues, particularly the relation between population growth and the Industrial Revolution.

Investigation of the change in health inevitably leads to consideration of population growth; but it is the modern rise of population as a whole which has to be explained, from some time in the eighteenth century when it began, until the present day. Unfortunately, data for England and Wales before registration of births and deaths in 1838 are so unreliable that it seems essential to begin with the later period, when birth rate, death rate and cause of death are available.

This evidence shows that the improvement of health after registration was due to a reduction of deaths from infectious diseases. Examination by cause of deaths which declined suggests that in order of importance the main influences were a rising standard of living (which had probably begun before 1838), improvements in the external environment (from about 1870) and specific medical measures in the twentieth century. Prevention or treatment of disease in the individual made little contribution in the nineteenth century, except in the case of vaccination against smallpox whose part in the total reduction of mortality after registration was small.

However the growth of population suggests that a significant improvement in health began much earlier, at least seventy years before registration of births and deaths. It cannot be attributed to specific medical measures which can hardly have been more effective in the eighteenth century than in the nineteenth. (An economic historian has suggested that inoculation against smallpox may account for the growth of population at that time, an explanation which has not impressed virologists who know the disease.) It also seems unlikely that the large increase of population between, say 1700 and 1840 , could be due to a fortuitous decline of mortality from infections, an explanation offered by economic historians in somewhat disguised form by reference to plague. If these possibilities are excluded, the growth of population must have been due to an improvement in living conditions, whether this led primarily to a rise in the birth rate (the explanation favoured by some economic historians) or a decline of mortality (the alternative, more likely to attract the support of biologists).

Some historians have been reluctant to accept that there could have been an improvement in standard of living in the eighteenth century. But there were large increases in home-produced food, sufficient to support a population which trebled between 1700 and 1850 without imported foodstuffs. In a period when nutrition was poor this change in itself might be sufficient to bring about a reduction of mortality large enough to account for the rise of population.

These conclusions place the emphasis on improvements in food supplies as the earliest and, probably, most important reason for the advance in health. But their effectiveness would have been greatly reduced if the expansion of population had not been restricted by reduction of the birth rate from about 1880 . Had the rate remained at its earlier level (approximately 35 per 1,000) the population of England and Wales would now be about 140 million, with effects on living conditions and health standards which can be imagined. It is therefore suggested that the main reasons for 


\section{Thomas McKeown}

improvement in health in probable order of importance were: a decline in the birth rate; a rise in the standard of living, first in food supplies and later in other respects; removal of specific hazards in the physical environment; and specific measures of preventing and treating disease in the individual.

What has been given here is no more than a sketch of a subject which deserves the fullest investigation, both in Britain and by extension to other countries where the increment in population and the time of changes such as industrialization were quite different. Until such inquiries have advanced to the point where their main conclusions are not in doubt, there will remain a serious deficiency in medical history and some difficult contemporary problems whose solution is prejudiced by lack of historical perspective.

\section{THE EVOLUTION OF MEDICAL PRACTICE}

The subjects so far discussed-influences on man's health, the tasks on which doctors have been engaged and the reasons for improvement in health-are all in a sense basic to a concept of human health and the part medicine and other influences play in preserving it. It is the lack of such insight which largely explains the misdirection of medical effort in the past, and the considerable confusion which still exists concerning the aims and methods of research and practice. This confusion is quite likely to increase, unless it is removed by the perspective the social history of medicine can uniquely provide. I want now to consider three other themes which illustrate the advantage of historical inquiry which takes as its starting point a contemporary problem. The first concerns medical practice.

There are few more important issues confronting medicine at the present time than the organization of medical practice. The fact that patterns of practice are very different in countries with a common language and similar social and political institutions suggests that medical practice has nowhere reached a satisfactory or stable form. For example, in some parts of Australia general practitioners have open access to hospitals and undertake services such as major surgery which would elsewhere be assigned to a specialist; in Britain, doctors are fairly sharply divided into general practitioner and consultant classes, the one working outside and the other inside hospital; in the United States there are wide variations in the pattern of practice but in some areas general practitioners of the traditional type no longer exist and all services are provided by specialists.

There are some grounds for concern about all these patterns: in Australia about the quality of surgery and other specialist services provided by general practitioners; in Britain about the viability of general practice divorced from hospital; and in the United States about the loss of personal medical care outside hospital. Attempts are being made to meet some of the difficulties-for example all three countries are seeking to strengthen or reinstate family practice by general practitioners-but it is an open question whether they will succeed without more fundamental changes in the organization of practice.

There are many subsidiary themes-the provision of home services, the use of the nurse or an assistant to the doctor in primary medical care, the need for personal care, the feasibility of family care and the need for services in the patient's home are 


\section{A Sociological Approach to the History of Medicine}

among them. But the central issue undoubtedly concerns the roles and relationships of the two major classes of medical worker-the general practitioner and the consultant-and their respective functions in and out of hospitals. It is on this issue that I believe an examination of the evolution of medical practice can be illuminating.

A great deal of attention has been given by historians to such matters as the early history of the physician, surgeon and apothecary, the founding of the Royal Colleges and the events which led to the First Medical Act of 1858. But if the primary aim is to provide perspective on the contemporary problem, the focus of interest is quite different: it is on the circumstances which brought about the present pattern of practice. With this knowledge it may be possible to see whether the roles and relationship of practitioner and consultant were determined largely by fortuitous influences which have left their mark on the practice of medicine. It may be useful to summarize some tentative conclusions.

The history of physician, surgeon and apothecary is well known, including the wide differences in their training, status and types of practice. It was the building of hospitals during the eighteenth and nineteenth centuries which eroded these differences, and replaced them with a new distinction between those who had a hospital appointment and those who had not.

Although the training of physician, surgeon and apothecary changed little during the eighteenth century, the traditional distinctions based on role and status began to break down. A sixteenth-century physician would have been horrified to be identified with a surgeon; but the new work in hospitals raised the status of the surgeon, and the College of Surgeons received its Royal Charter in 1800. The important distinction was then between doctors appointed at the large voluntary hospitals, whether as physicians or surgeons, and those who were not.

At the same time the position of the apothecary was also changing. Although he had been visiting patients and prescribing for more than a century, it was not until 1703 that he was legally entitled to do so, provided he made no charge. During the eighteenth century he became established as the general practitioner of the poor and middle classes. His training required six months' experience in hospital or dispensary and some apothecaries actually worked in hospitals. In the early nineteenth century the division between apothecaries and other practitioners was further diminished when some took a second qualification. It was no longer unknown for a doctor to practise legally as surgeon and apothecary, or even as physician and apothecary. This confusion of training, role and status was part of the background of the 1858 Medical Act.

By providing a common basis for training and registration the Medical Acts of 1858 and 1886 finally removed the long-standing divisions between physician, surgeon and apothecary. But by this time the new, and from a present-day viewpoint more significant, distinction between consultant and practitioner was well established. It was a distinction based, not on material differences in experience or competence, but on hospital appointments; the large voluntary hospitals in London and in the provinces were closed to the general practitioner. There was indeed no true consultant, in the sense of one who sees only selected patients referred to him by other doctors, and in 1876 the British Medical Journal described the country consultant as 'the general 


\section{Thomas McKeown}

practitioner who owes his position to the fact of his holding an appointment in connection with a country hospital.' The consultant was indeed little more than 'a practitioner among the rich', and according to the Journal the difference between the general practitioner and the consultant really resolved itself into a difference of fees. It was not until the twentieth century that the state of medical knowledge really justified the emergence of a consultant class.

This short account is no more than a preliminary examination of a subject which deserves to be carefully investigated: the evolution of the relationship between general practitioner and consultant. But it does show that this distinction began long before it was justified by the state of medical knowledge; it also suggests that the exclusion of general practitioners from hospital was not a logical development, but resulted from the fact that before the eighteenth century almost all practice was domiciliary, and as hospitals developed there was strong competition for appointments in which, inevitably, not all were successful.

I believe that this knowledge of the evolution of medical practice, coupled with awareness of the wide variations which exist at the present time, helps us to approach the contemporary issues with open minds. It enables us to see that our pattern of practice is of relatively recent origin, that it was influenced largely by ephemeral circumstances and that the roles and relationship of general practitioner and consultant should be reconsidered in the light of modern requirements and without assuming that what now exists is best because it is familiar.

\section{THE HISTORY OF THE PUBLIC HEALTH SERVICE}

The history of public health has been written very fully, but not in terms which throw much light on the problems which now confront the service. The central questions, I suggest, are its reorientation in countries where public responsibility have been accepted for all, or nearly all therapeutic as well as preventive services, and behind this the still larger issue of public competence and responsibility for administration of health services. In this context we turn to history for an understanding of the circumstances which determined the form, limitations and local government control of public health rather than for a discussion of Acts of Parliament, the hypochondria of Florence Nightingale or the removal of the handle of the Broad Street pump.

The introduction of environmental services by the 1848 Public Health Act raises two questions: one is why they were delayed so long, in view of measures such as quarantine and isolation which were taken centuries earlier; the other is why having been delayed they were established before, if only a short time before, the bacterial origin of infection was understood. A tentative answer to the first question is that the earlier measures were directed to epidemic rather than to endemic infections; and to the second, that public action was a sequel to ideas, about the relationship between living conditions and health, which had been developing since the early eighteenth century. Chadwick, in spite of his heresy concerning the nature of infectious disease, outlined very precisely the programme subsequently endorsed by bacteriologists: 'That the primary and most important measures, and at the same time the most practical, and within the recognized province of public administration, 


\section{A Sociological Approach to the History of Medicine}

are drainage, the removal of all refuse from habitations, streets and roads, and the improvement of the supplies of water.' In this way, after about a million years' experience, men came to recognize the step which is second in importance, or perhaps more accurately third, among measures which can be taken to improve human health.

The events which led local authorities to enter the field of personal health services soon after the beginning of this century are well known, not so much because they have attracted the interest of medical historians as because they are incorporated in the writings of the Fabians and particularly of the Webbs and Shaw. They publicized the extent of ill health and the inadequacies of medical services, and enlivened the debate concerning the roles of private and public sectors in medical finance and administration. The issues then raised and the decisions concerning them were of outstanding importance and have left their mark on medical services to the present day.

Broadly there were two proposals: one, that there should be a unified state medical service, based on public health principles and administered by local government; the other that the additional public services should be provided by doctors in private practice. The full implementation of either proposal might have prevented the division between preventive and treatment services. The medical staffs of public health authorities were then extensively engaged in treatment as well as prevention of disease, and had both been sanctioned by Parliament, a unified service under local government would have resulted. Alternatively, had general practitioners been permitted to undertake the new work in schools and later in welfare clinics, the division might again have been avoided. In this case the later attitude of doctors to local authority administration and payment by salary might have been quite different. The compromise which made prevention a public responsibility and left cure in private hands had a profound impact on subsequent developments and, with the decision in 1911 not to assign national health insurance administration to local government, largely determined the framework which was retained in the National Health Service. It also led to the opposition of general practitioners and consultants to local authority administration of medical services.

The divided administration of local health services is, apparently, to be eliminated soon, at least in Britain; the large question concerning administration by elected or appointed bodies remains. In favour of local government it is said that the public which pays should manage the service; against, that experience of the public health service teaches that medical services are better in other hands. The answer to this question should turn on a penetrating analysis of the kinds of problems with which local health authorities have hitherto dealt and their degree of success in solving them. With this knowledge it would be possible to turn to the quite different problems which will present in future, and to enquire whether in the light of past experience they should be assigned to local government or to appointed bodies. In the event the decision in Britain is likely to be taken on pragmatic grounds and it is questionable whether the efforts of social historians could have made a difference. But it certainly would be in the interests of many countries which have not passed the point of no return to see the history of public health in Britain written in relation to contemporary issues rather than in the traditional descriptive terms. 


\section{THE DEVELOPMENT OF HOSPITALS}

It is hardly necessary to stress the importance of hospitals at the present time. They are the most costly component of medical services and the one whose expenditure is most difficult to control; they are the centres of research and training and have the influence derived from these activities; and since the arrangement of buildings and plant has a powerful influence on research and practice, they largely determine the direction of medical effort.

In Britain most hospitals date from the eighteenth and nineteenth centuries and now require substantial extension and reconstruction. It is essential that the new development should correct the mistakes of the past and, so far as possible, take account of future trends.

I believe that the most serious problems confronting hospitals derive from their fragmentation, particularly the separation of mental, chronic and acute hospitals, but also the isolation of many acute facilities for patients such as women and children and for diseases such as those affecting the central nervous and cardiovascular systems. An examination of the historical development of hospitals explains these anomalies, attributing them to the joint influences of the casual way in which hospitals were founded, and the interpretation of their role which led acute hospitals to reject certain kinds of work.

It could be said of the hospital under the monasteries as Robert Frost said of home, that it was the place 'where when you've got to go there, they've got to take you in.' But although the original purpose of the new hospitals founded by charity from the eighteenth century was to care for the sick poor, they soon began to admit only patients considered to be curable or, more accurately, likely to recover without treatment. They first excluded diseases such as infectious and venereal diseases, along with children and pregnant women, but by the mid-nineteenth century admissions were largely restricted to short-term illness.

Some of the work rejected was taken up by other voluntary bodies; but there were three classes of patients which were beyond the means of voluntary bodies and largely outside the range of charitable appeal: the infectious, the mentally ill and the destitute sick. Their exclusion led to a public hospital system and largely influenced its form.

Mental patients were the first for whom substantial public provision was made from 1848 when Parliament permitted (and later required) the building of county asylums for paupers. The founding of the second major division of the public hospital system was an unplanned consequence of revision of the Poor Law. The Amendment Act of 1834 was intended to end domiciliary aid by making it necessary for ablebodied paupers to enter an institution before they received public assistance. But in admitting the destitute, the Poor Law Authorities could not avoid admitting the sick, and by the end of the century most of the country's hospital beds were under the control of this unintended and ill-suited authority.

In recognition of the inadequacy of the Poor Law Services, Parliament in 1867 authorized the construction of separate infirmaries, designed as hospitals and planned to follow the practices and, so far as possible, the standards of the voluntary hospitals. But the infirmaries also began to restrict admissions to acute cases and to accept patients above the pauper class. This meant that the formidable problem of caring 


\section{A Sociological Approach to the History of Medicine}

for the indigent sick remained with the mixed workhouse, the institution least able to deal with it.

The other arm of the hospital service owed its origin to the failure of the voluntary hospitals to make provision for infectious disease. In 1867 Parliament authorized construction of fever hospitals and this led to the beginning of the municipal hospital system. At first it was concerned only with scarlet fever, enteric, typhus and smallpox, but later the work was extended to include other fevers and, after the first World War, by addition of tuberculosis and maternity. Local sanitary authorities were also permitted to provide general hospitals but they had done so in only a few cases by 1929 when the functions of the Poor Law Authorities were transferred to the major local authorities.

This transfer reduced the number of hospital administrations to two, one public and the other private. It did not affect the widespread fragmentation of hospitals constructed during the eighteenth, nineteenth and early twentieth centuries and still reflected in the haphazard services of every major town. Inadequate and badly located sites, hospitals too small to support essential services and separation of related activities are the price that is still paid for the unplanned development. Their fragmentation is the origin of some of the most intractable problems confronting hospitals, including the division of work into favoured and depressed areas, staffing difficulties of mental, chronic and some other hospitals, uneconomic management and lack of flexibility in face of changing needs. Yet many people, including doctors, are still prepared to defend the traditional anomalies: small hospitals; fragmented facilities; and a division between acute and chronic services.

I believe that historical research can make an invaluable contribution to correcting such misapprehensions, and indeed a rational approach to present and future hospital developments is hardly possible without it. But what is required for this purpose is not the traditional account of the history of individual hospitals, or the advances in medical knowledge with which they were associated, or the lives of the notable figures who have worked in them. All these subjects have their interest and it has been catered for generously in histories of medicine. The task which remains for the social historian is to interpret the evolution of hospitals against the background of the major problems which now confront them: provision of services of adequate standard for all classes of patients; rational accommodation to the uses and limitations of technology; reorientation of the services of teaching centres; restriction of costs; extension of research into neglected areas, particularly in the applied field. Without recognition of such problems the social history of medicine will be an esoteric study; and without historical perspective medical science and service will continue to drift. 